\title{
Epicardial Fat Thickness and its Association as a Risk Factor for Coronary Artery Disease
}

\author{
Sai Swaroop ${ }^{1}$, Saroj Kumar Tripathy ${ }^{1}$, Nirmal Chandra Sahu1, Biswajit Das², Milan Satpathy² \\ ${ }^{1}$ Department of Medicine, SCB Medical College, Cuttack, India \\ ${ }^{2}$ Department of Cardiology, SCB Medical College, Cuttack, India \\ Email: sarojtripathy1@hotmail.com
}

How to cite this paper: Swaroop, S., Tripathy, S.K., Sahu, N.C., Das, B. and Satpathy, M. (2019) Epicardial Fat Thickness and its Association as a Risk Factor for Coronary Artery Disease. World Journal of Cardiovascular Diseases, 9, 193-201.

https://doi.org/10.4236/wjcd.2019.93017

Received: January 21, 2019

Accepted: March 15, 2019

Published: March 18, 2019

Copyright (c) 2019 by author(s) and Scientific Research Publishing Inc. This work is licensed under the Creative Commons Attribution-NonCommercial International License (CC BY-NC 4.0). http://creativecommons.org/licenses/by-nc/4.0/

\begin{abstract}
Background of study aims and objective: Epicardial fat thickness is a novel parameter for predicting outcome and assessment of severity of coronary artery disease. Our present study aims to establish an association between epicardial fat thickness and coronary artery disease. Materials \& Methods: Patients of suspected CAD underwent coronary angiography. 100 subjects proven as confirmed cases were included in the study. Routine clinical examination, risk factor profile and anthropometric variables were also done. Severity of CAD was assessed using Gensini Score. Epicardial fat thickness was measured using 2D ECHO. For comparative analysis, 50 healthy individuals were also included in the study. Results: Epicardial fat thickness was significantly higher in cases $(7.53 \pm 1.79 \mathrm{~mm})$ than controls $(4.24 \pm 1.09 \mathrm{~mm})$. Female sex, hypertension, dyslipidemia, obesity were observed to affect EFT significantly. No difference in mean EFT was observed with age, diabetes, smoking, ECG changes and arterial territory involvement. BMI and Gensini scores both showed strong positive correlation with epicardial fat thickness. Conclusion: Epicardial fat thickness is associated and linearly correlates with onset and severity of CAD.
\end{abstract}

\section{Keywords}

Epicardial Fat Thickness, Gensini Score, Coronary Angiography

\section{Introduction}

Coronary Artery Disease (CAD) is a complex chronic inflammatory disease characterized by remodeling and narrowing of coronary arteries supplying the heart most commonly due to atherosclerotic changes [1]. It has a complex and multifactorial etiopathogenesis with an unpredictable natural course of disease. 
Globally, the incidence and mortality due to CAD has assumed epidemic proportions. In India over the past few years, there has been a shift in disease trend with increasing burden of non communicable diseases with CAD being the forerunner [2].

Epicardial fat thickness (EFT) is a promising novel marker for assessing risk and progression of CAD. It is the true visceral depot of heart with close proximity to the myocardium and shares the same microcirculation [3]. Epicardial fat has shown to produce adipokines and other proinflammatory cytokines, which plays an important role in accelerated atherosclerosis and subsequent CAD [4]-[9]. It has also shown to have association with established risk factors of CAD such as diabetes, dyslipidemia, hypertension and smoking [10] [11] [12] [13] [14]. Although epicardial fat is a marker of visceral adiposity, there is evidence of its relation with increased subcutaneous adipose tissue \& body mass index [14].

The aim of the present study was to assess the association of epicardial fat thickness with occurrence and severity of CAD and also its relation with other conventional risk factors.

\section{Materials and Methods}

\subsection{Study Design}

The study was an observational cross sectional study conducted at SCB Medical College, Cuttack over a period of one year. 100 patients were enrolled in the study all of whom were angiographically proven cases of coronary artery disease. For comparative analysis 50 healthy subjects were taken who did not have any conventional CAD risk factors. Both the groups were matched for age and sex. Written consent was obtained from every subject enrolled in the study.

\subsection{Inclusion Criteria}

Confirmed cases of coronary artery disease proven by coronary angiogram were taken as cases whereas controls were healthy individuals.

\subsection{Exclusion Criteria}

All cases of previously diagnosed CAD who underwent CABG or PCI, Valvular Heart Disease, Cardiomyopathies, COPD, Chronic kidney and chronic liver disease, pericardial or pleural effusion and poor echo window patients were excluded from the study.

\subsection{Methodology}

Body Mass Index was calculated using Quetelet's Index. Subjects were grouped as normal (BMI $\leq 24.99)$, pre obese (BMI 25 - 29.99) and obese (BMI $\geq 30$ ). Hypertension was defined as per the criteria of American College of Cardiology (Normal: < 120/80, Elevated: 120 - 129/ < 80, Stage 1: 130 - 139/80 - 89, Stage 2: $>140 / 90$ ) [15]. Diabetes Mellitus was defined as per the criteria of American Diabetes Association [16]. Hyperlipidemia was defined as total cholesterol $\geq 220$ 
$\mathrm{mg} / \mathrm{dl}$ or triglycerides $\geq 150 \mathrm{mg} / \mathrm{dl}$ [17].

Two-Dimensional Echocardiography was done for assessment of regional wall motion abnormality as well as epicardial fat thickness. Epicardial fat thickness was measured on the free wall of right ventricle during end systole as there is compression of epicardial fat during diastole (Figure 1). Standard parasternal long and short axis views were used [18] [19]. Average of 3 readings were taken and used for data analysis.

Coronary Angiography was performed and patients with occlusion were included in the study. Judkin' technique was used via femoral or radial artery approach. Gensini Scoring System was used for quantitative assessment of severity of CAD [20].

\subsection{Statistical Analysis}

All data were collected, tabulated, and statistically analyzed using SPSS for Windows (version 21.0; SPSS Inc., Chicago, Illinois, USA).Continuous variables were expressed in Means $\pm \mathrm{SD}$. Continuous data which was skewed was expressed in Median values and interquartile range. For comparison between continuous variables, Student $\mathrm{t}$ Test (Independent Samples $\mathrm{t}$ Test) was used when variables were two in no. and One Way ANOVA was used when 3 or more variables were taken. For comparison between two categorical variables Chi Square Test was used. For comparison between skewed data Non Parametric test (Mann Whitney Test \& Independent Sample Kruskal Wallis Test) was used. To establish correlation between variables Pearson's Correlation was used when data was normally distributed and Spearman's Correlation was used when data was skewed. $\mathrm{P}$ value $\leq 0.05$ was considered statistically significant, and a $95 \%$ confidence interval was used.

\section{Results}

\subsection{Demographic Profile}

The mean age of cases was 55.99 yrs and that of controls was 52.70 yrs (Table 1 ). Out of the 100 cases 70 were males and 30 females whereas among 50 controls 34 were males and 16 females. BMI of cases and controls was 26.56 and 24.41 respectively (Table 1). Various risk factors, ECG changes and ECHO findings were observed in cases.

\subsection{EFT vs Various Parameters}

Various independent risk factors for CAD were compared with EFT. The mean EFT did not show any statistically significant variation with increasing age with very weak correlation (Table $1 \&$ Table 7 ). The CAD group showed significantly higher values of mean EFT among females as compared to males. However this difference was absent in the control group (Table 2). In subjects with higher $\mathrm{BMI}$, EFT was found to be significantly higher for both the cases and controls with strong correlation (Table 7). When compared with the established risk 


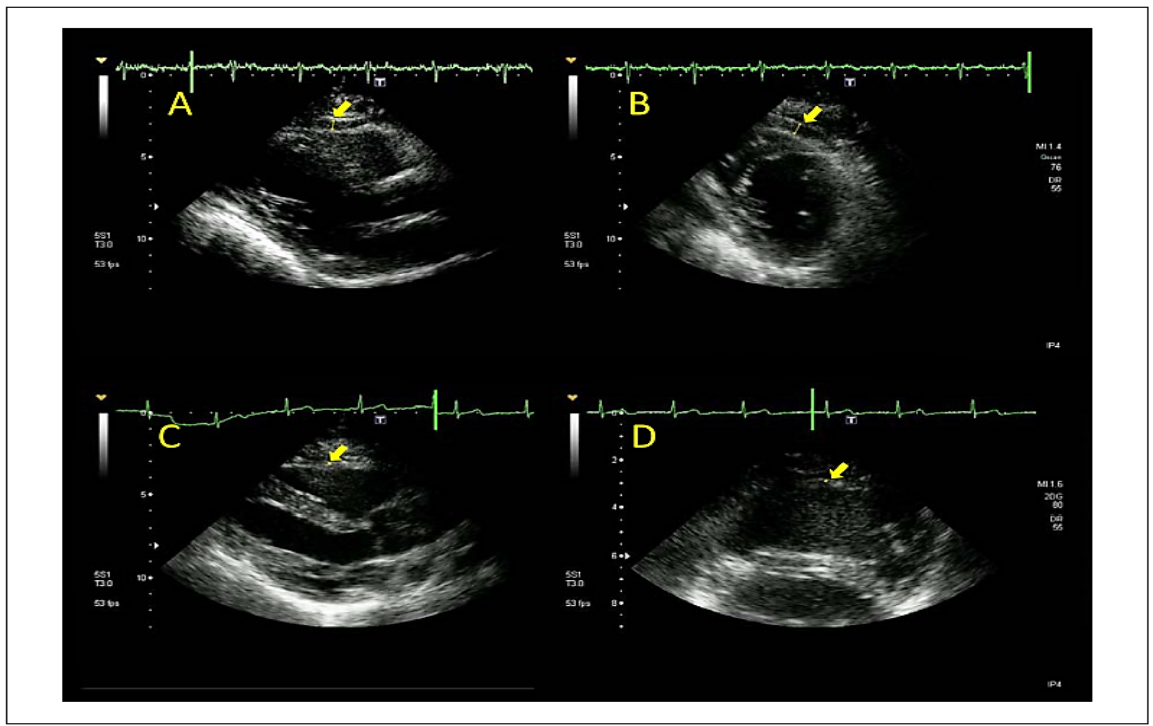

Figure 1. Epicardial fat measurement by echocardiography in the parasternal longitudinal and transverse parasternal views. Epicardial fat (indicated by arrows) with increased thickness (1(A) and $1(B))$ and minimum epicardial fat $(1(C)$ and $1(D))$.

Table 1. Demographic Parameters in Cases and Controls.

\begin{tabular}{cccc}
\hline \multicolumn{4}{c}{ Demographic Parameters in Cases and Controls } \\
\hline Variables & Cases (Mean \pm SD) & Controls (Mean \pm SD) & p Value \\
\hline Age (in yrs) & $55.99 \pm 10.85$ & $52.70 \pm 9.84$ & 0.06 \\
BMI & $26.56 \pm 4.02$ & $24.41 \pm 3.39$ & 0.001 \\
EFT(in mm) & $7.53 \pm 1.79$ & $4.24 \pm 1.09$ & 0.0001 \\
\hline
\end{tabular}

Table 2. Gender variation in Epicardial fat thickness.

\begin{tabular}{cccc}
\hline \multicolumn{3}{c}{ Gender variation in Epicardial fat thickness } \\
\hline \multirow{2}{*}{ Study Population } & \multicolumn{2}{c}{ Epicardial Fat Thickness (in mm) } & \multirow{2}{*}{ p Value } \\
\cline { 2 - 3 } & Males & Females & \\
\hline Cases & $7.24 \pm 1.73$ & $8.22 \pm 1.77$ & 0.05 \\
Controls & $4.30 \pm 1.14$ & $4.12 \pm 1.03$ & 0.59 \\
\hline
\end{tabular}

factors, higher EFT was found in hypertensives and dyslipidemic subjects but not in diabetics and smokers (Table 3). ECG changes and regional wall motion abnormality on 2D ECHO did not have any significant influence on EFT (Table $4 \&$ Table 5). The group with proven CAD had higher EFT than the control group with statistically significant difference (Table 6).

\subsection{EFT vs Severity of CAD (Assessed by Gensini Score)}

Severity of CAD as assessed by Gensini score was compared with EFT. Subjects with higher Gensini scores had statistically significant higher mean EFT. A 
Table 3. Distribution of risk factors and mean Epicardial fat thickness.

\begin{tabular}{cccc}
\hline \multicolumn{4}{c}{ Distribution of risk factors and mean Epicardial fat thickness } \\
\hline Risk Factors & $\begin{array}{c}\text { EFT in cases with risk factors } \\
\text { (in mm) }\end{array}$ & $\begin{array}{c}\text { EFT in cases without risk factors } \\
\text { (in mm) }\end{array}$ & p Value \\
\hline Hypertension & $8.08 \pm 1.65(\mathrm{n}=44)$ & $7.10 \pm 1.79(\mathrm{n}=56)$ & 0.006 \\
Diabetes & $7.48 \pm 1.93(\mathrm{n}=36)$ & $7.56 \pm 1.72(\mathrm{n}=64)$ & 0.84 \\
Dyslipidemia & $8.20 \pm 1.76(\mathrm{n}=35)$ & $7.17 \pm 1.70(\mathrm{n}=65)$ & 0.005 \\
Smoking & $7.23 \pm 1.71(\mathrm{n}=24)$ & $7.63 \pm 1.81(\mathrm{n}=76)$ & 0.33 \\
\hline
\end{tabular}

Table 4. Epicardial fat thickness with relation to ECG changes.

\begin{tabular}{lcccc}
\hline \multicolumn{3}{c}{ Epicardial fat thickness with relation to ECG changes } & \multirow{3}{*}{ p Value } \\
\cline { 2 - 4 } & \multicolumn{3}{c}{ ECG Findings } \\
\cline { 2 - 4 } & STEMI & NSTEMI & Normal & \\
\hline Epicardial fat thickness (in mm) & $7.49 \pm 1.73$ & $7.80 \pm 1.92$ & $7.40 \pm 2.07$ & 0.79 \\
\hline
\end{tabular}

Table 5. Epicardial fat thickness with relation to 2D ECHO Findings.

\begin{tabular}{lcccc}
\hline \multicolumn{3}{c}{ Epicardial fat thickness with relation to ECG changes } & \multirow{2}{*}{ p Value } \\
\cline { 2 - 4 } & \multicolumn{3}{c}{ ECG Findings } \\
\cline { 2 - 4 } & STEMI & NSTEMI & Normal & \\
\hline Epicardial fat thickness (in mm) & $7.49 \pm 1.73$ & $7.80 \pm 1.92$ & $7.40 \pm 2.07$ & 0.79 \\
\hline
\end{tabular}

Table 6. Epicardial fat thickness in cases and controls.

\begin{tabular}{lccc}
\hline \multicolumn{3}{c}{ Epicardial fat thickness in cases and controls } & \multirow{2}{*}{ Study population } \\
& \multicolumn{2}{c}{ P Value } \\
\cline { 2 - 3 } & Cases & Controls & \\
\hline Epicardial fat thickness (in mm) & $7.53 \pm 1.79$ & $4.24 \pm 1.09$ & 0.001 \\
\hline
\end{tabular}

strong correlation between severity of CAD and EFT was also established (Table 7 \& Figure 2).

\section{Discussion}

Epicardial fat thickness has been identified as an important tool in early diagnosis and predicting outcome in coronary artery disease [21]. Various parameters were compared with epicardial fat thickness and promising results were obtained. The group with proven CAD had higher mean EFT as compared to normal individuals which is consistent with multiple studies worldwide [22] [23] [24]. Although age being an important predictor of CAD, no such result was obtained in our study. Female cases had higher values of EFT as compared to male counterparts [25]. However, no such difference was observed in healthy individuals. A possible explanation for this might be the absence of CAD risk factors in the 
Table 7. Correlation between EFT and different variables.

\begin{tabular}{ccc}
\hline & \multicolumn{1}{c}{ Correlation between EFT and different variables } \\
\hline Variables & $\mathrm{r}$ Value & $\mathrm{p}$ Value \\
& 0.029 (Cases) & 0.86 (Cases) \\
Age & 0.12 (Controls) & 0.089 (Controls) \\
& 0.75 (Cases) & 0.001 (Cases) \\
BMI & 0.68 (Controls) & 0.001 (Controls) \\
Gensini Score & 0.89 & 0.001 \\
\hline
\end{tabular}

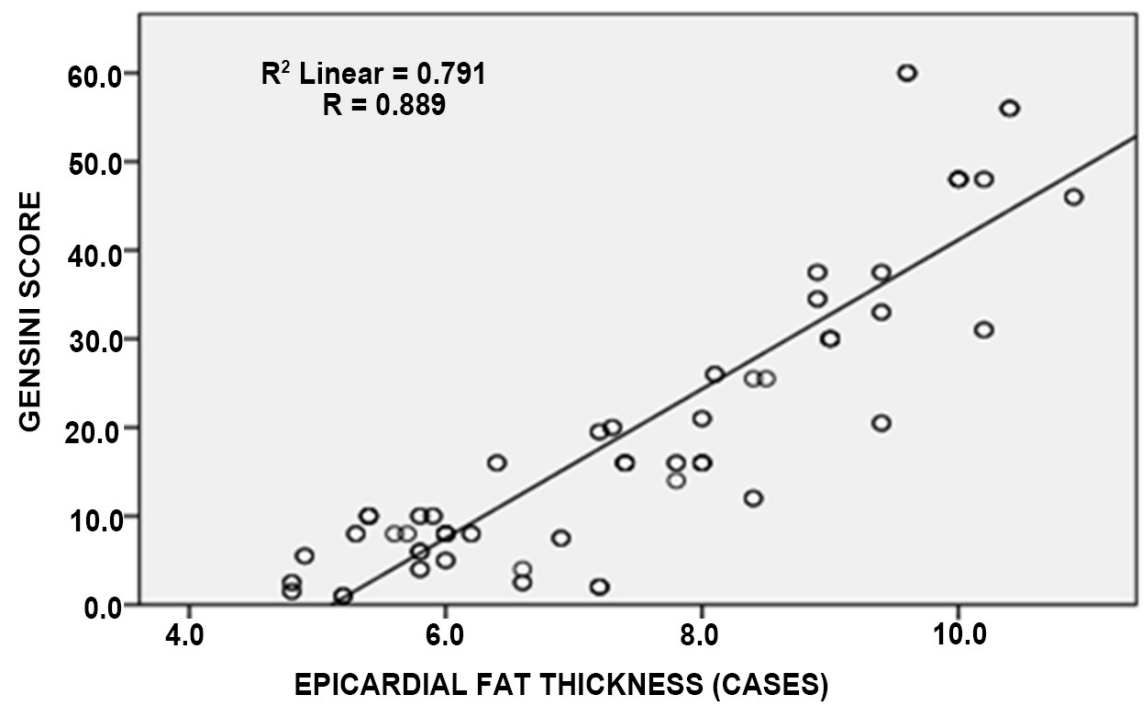

Figure 2. Correlation between eft and gensini score.

healthy population. Obesity was associated and correlated strongly with the values of EFT [11] [25] [26]. Hypertension [11] [12] [13] [27] and dyslipidemia [11] [13] [27] were found to be an independent factor influencing epicardial fat. In our study diabetic with CAD did not show any increased values of EFT [22] [23] [28]. This might be due to the high rates of death in diabetics due to silent myocardial infarction. Smoking status of the patients did not alter the epicardial fat [11] [22] [23] [25]. ECG changes of CAD patients and territorial regional wall motion abnormality on 2D ECHO had no association with EFT. Severity of CAD assessed by Gensini score had a strong positive correlation with epicardial fat.

Epicardial fat thickness can prove to be an important screening tool in general population for early diagnosis and treatment of CAD with specific strategies directed towards the same.

\section{Limitations}

- The present study being a cross sectional study could not establish causality between EFT and CAD. A prospective study needs to be undertaken for the same in future.

- The controls being healthy individuals were devoid of risk factors. Studies in non CAD patients with presence of risk factors would be more appropriate. 
- Sample size of our study was 100 patients. Study involving large sample size would yield better results.

- As it is a hospital based study, it might not give the exact representation of the entire population.

\section{Conclusion}

Epicardial fat thickness significantly correlated with the severity of coronary artery stenosis angiographically and can be used for risk stratification. Echocardiography is an easy, inexpensive and non-invasive method for measurement of epicardial fat. There are several established CAD risk factors, such as obesity, hypertension, diabetes mellitus, smoking and dyslipidemia, but among these well known risk factors, epicardial fat thickness emerged as an independent predictor of CAD. In order to include it in the armamentarium of conventional tools for assessment of coronary artery disease, a larger study with promising results needs to be done. However, in the present scenario, we can safely conclude that this novel parameter holds great importance for assessment of CAD in future.

\section{Conflicts of Interest}

The authors declare no conflicts of interest regarding the publication of this paper.

\section{References}

[1] Montalescot, G., et al. (2013) Task Force on the Management of Stable CAD of ESC. European Heart Journal, 34, 2949-3003.

[2] Gupta, R., Mohan, I. and Narula, J. (2016) Trends in Coronary Heart Disease Epidemiology in India. Annals of Global Health, 82, 3007-3015. https://doi.org/10.1016/j.aogh.2016.04.002

[3] Iacobellis, G. and Willens, H.J. (2009) Echocardiographic Epicardial Fat: A Review of Research and Clinical Applications. Journal of the American Society of Echocardiography, 22, 1311-1319. https://doi.org/10.1016/j.echo.2009.10.013

[4] Shioji, K., Moriguchi, A., Moriwaki, S., et al. (2005) Hypoadiponectinemia Implies the Development of Atherosclerosis in Carotid and Coronary Arteries. Journal of Cardiology, 46, 105-112.

[5] Sharma, A.M. (2002) Adipose Tissue: A Mediator of Cardiovascular Risk. International Journal of Obesity and Related Metabolic Disorders, 26, S5-S7. https://doi.org/10.1038/sj.ijo.0802210

[6] Libby, P., Ridker, P.M. and Maseri, A. (2002) Inflammation and Atherosclerosis. Circulation, 105, 1135-1143. https://doi.org/10.1161/hc0902.104353

[7] Cheng, K.H., Chu, C.S., Lee, K.T., et al. (2008) Adipocytokines and Proinflamatory Mediators from Abdominal and Epicardial Adipose Tissue in Patients with Coronary Artery Disease. International Journal of Obesity, 32, 268-274. https://doi.org/10.1038/sj.ijo.0803726

[8] Otsuka, F., Sugiyama, S., Kojima, S., et al. (2006) Plasma Adiponectin Levels Are Associated with Coronary Lesion Complexity in Men with Coronary Artery Dis- 
ease. Journal of the American College of Cardiology, 48, 1155-1162.

https://doi.org/10.1016/j.jacc.2006.05.054

[9] Iacobellis, G., Pistilli, D., Gucciardo, M., et al. (2005) Adiponectin Expression in Human Epicardial Adipose Tissue in Vivo Is Lower in Patients with Coronary Artery Disease. Cytokine, 29, 251-255.

[10] Akyurek, O., Efe, D. and Kaya, Z. (2015) Epicardial Fat Thickness and its Association with Cardiovascular Risk in Patients with Type 2 Diabetes Mellitus. European Journal of General Medicine, 12, 131-135.

[11] Ahn, S.G., Lim, H.S., Joe, D.Y., Kang, S.J., Choi, B.J. and Choi, S.Y. (2008) Relationship of Epicardial Adipose Tissue by Echocardiography to Coronary Artery Disease. Heart, 94, e7. https://doi.org/10.1136/hrt.2007.118471

[12] Bachar, G., Khasminsky, V., Dicker, D., Kornowski, R. and Atar, E. (2014) Increased Epicardial Adipose Tissue Thickness in Hypertensive Patients: MDCT Study. European Society of Radiology, 1, 1-25.

[13] El-Aziz, A., Walaa, F., Ahmed, M.K. and Badr, W.A. (2017) Association of Echocardiographic Epicardial Fat with the Extent of Coronary Artery Disease. Menoufia Medical Journal, 30, 842-849.

[14] Cavalcante, J.L., et al. (2012) Association of Epicardial Fat, Hypertension, Subclinical Coronary Artery Disease and Metabolic Syndrome with Left Ventricular Diastolic Dysfunction. American Journal of Cardiology, 110, 1793-1798.

https://doi.org/10.1016/j.amjcard.2012.07.045

[15] Whelton, P.K., Carey, R.M., Aronow, W.S., et al. (2018) Guideline for the Prevention, Detection, Evaluation, and Management of High Blood Pressure in Adults: A Report of the American College of Cardiology/American Heart Association Task Force on Clinical Practice Guidelines. Journal of the American College of Cardiology, 71, e127-e248. https://doi.org/10.1016/j.jacc.2017.11.006

[16] (1997) Report of the Expert Committee on the Diagnosis and Classification of Diabetes Mellitus. Diabetes Care, 20, 1183-1197.

https://doi.org/10.2337/diacare.20.7.1183

[17] National Cholesterol Education Program (NCEP) Expert Panel on Detection, Evaluation, and Treatment of High Blood Cholesterol in Adults (Adult Treatment Panel, III) (2002) Third Report of the National Cholesterol Education Program (NCEP) Expert Panel on Detection, Evaluation, and Treatment of High Blood Cholesterol in Adults (Adult Treatment Panel III): Final Report. Circulation, 106, 3143-3421. https://doi.org/10.1161/circ.106.25.3143

[18] Iacobellis, G., Assael, F., Ribaudo, M.C., et al. (2003) Epicardial Fat from Echocardiography: A New Method for Visceral Adipose Tissue Prediction. Obesity Research, 11, 304-310. https://doi.org/10.1038/oby.2003.45

[19] Iacobellis, G., Ribaudo, M.C., Assael, F., et al. (2003) Echocardiographic Epicardial Adipose Tissue Is Related to Anthropometric and Clinical Parameters of Metabolic Syndrome: A New Indicator of Cardiovascular Risk. The Journal of Clinical Endocrinology \& Metabolism, 88, 5163e8.

[20] Sullivan, D.R., Marwick, T.H. and Freedman, S.B. (1990) A New Method of Scoring Coronary Angiograms to Reflect Extent of Coronary Atherosclerosis and Improve Correlation with Major Risk Factors. American Heart Journal, 119, 1262-1267. https://doi.org/10.1016/S0002-8703(05)80173-5

[21] Bettencourt, N., Toschke, A.M., Leite, D., et al. (2012) Epicardial Adipose Tissue Is an Independent Predictor of Coronary Atherosclerotic Burden. International Journal of Cardiology, 28, 26-32. https://doi.org/10.1016/j.ijcard.2010.12.085 
[22] Meenakshi, K., Rajendran, M., Srikumar, S. and Chidambaram, S. (2016) Epicardial Fat Thickness: A Surrogate Marker of Coronary Artery Disease-Assessment by Echocardiography. Indian Heart Journal, 68, 336-341. https://doi.org/10.1016/j.ihj.2015.08.005

[23] Jeong, J.W., Jeong, M.H., Yun, K.H., Oh, S.K., Park, E.M. and Kim, Y.K. (2007) Echocardiographic Epicardial Fat Thickness and Coronary Artery Disease. Circulation Journal, 71, 536-539. https://doi.org/10.1253/circj.71.536

[24] Sinha, et al. (2016) Epicardial Adipose Tissue Thickness and Its Association with the Presence and Severity of Coronary Artery Disease in Clinical Setting: A Cross-Sectional Observational Study. Journal of Clinical Medicine Research, 8, 410-419. https://doi.org/10.14740/jocmr2468w

[25] Park, et al. (2016) Echocardiographic Epicardial Fat Thickness Is a Predictor for Target Vessel Revascularization in Patients with ST Elevation Myocardial Infarction. Lipids in Health and Disease, 15, 194.

https://doi.org/10.1186/s12944-016-0371-8

[26] Tanami, et al. (2015) Lack of Association between Epicardial Fat Volume and Extent of Coronary Artery Calcification, Severity of Coronary Artery Disease, or Presence of Myocardial Perfusion Abnormalities in a Diverse, Symptomatic Patient Population. Circulation: Cardiovascular Imaging, 8, e002676. https://doi.org/10.1161/CIRCIMAGING.114.002676

[27] Aydin, A.M., Kayali, A., Poyraz, A.K. and Aydin, K. (2015) The Relationship between Coronary Artery Disease and Pericoronary Epicardial Adipose Tissue Thickness. Journal of International Medical Research, 43, 17-25. https://doi.org/10.1177/0300060514558323

[28] Picard, F.A., et al. (2014) Epicardial Adipose Tissue Thickness Correlates with the Presence and Severity of Angiographic Coronary Artery Disease in Stable Patients with Chest Pain. PLoS ONE, 9, e110005. https://doi.org/10.1371/journal.pone.0110005 